\title{
Partially Reversible Photoinduced Chemical Changes in a Mixed-Ion Perovskite Material for Solar Cells
}

Ute B. Cappel, ${ }^{*}{ }^{\dagger}$ Sebastian Svanström, ${ }^{\dagger}$ Valeria Lanzilotto, ${ }^{\dagger \dagger}$ Fredrik O. L. Johansson, ${ }^{\dagger}{ }^{\dagger}$ Kerttu Aitola, ${ }^{\S}$ Bertrand Philippe, ${ }^{\dagger}$ Erika Giangrisostomi, ${ }^{\|}$Ruslan Ovsyannikov, ${ }^{\|}$Torsten Leitner, ${ }^{\dagger,{ }^{\dagger}}$ Alexander Föhlisch, ${ }^{\|, \perp}$ Svante Svensson, ${ }^{\dagger, \dagger}$ Nils Mårtensson, ${ }^{\dagger, \ddagger}$ Gerrit Boschloo, ${ }^{\S}$ Andreas Lindblad, ${ }^{\dagger, \ddagger(0)}$ and Håkan Rensmo*,†

${ }^{\dagger}$ Division of Molecular and Condensed Matter Physics, Department of Physics and Astronomy, Uppsala University, P.O. Box 516, 75120 Uppsala, Sweden

${ }^{\ddagger}$ Uppsala-Berlin Joint Laboratory on Next Generation Photoelectron Spectroscopy, Albert-Einstein-Str. 15, 12489 Berlin, Germany

${ }^{\S}$ Department of Chemistry—Ångström Laboratory, Uppsala University, P.O. Box 523, 75120 Uppsala, Sweden

"Institute Methods and Instrumentation for Synchrotron Radiation Research, Helmholtz-Zentrum Berlin GmbH, Albert-Einstein-Straße 15, 12489 Berlin, Germany

${ }^{\perp}$ Institute of Physics and Astronomy, University of Potsdam, Karl-Liebknecht-Straße 24/25, 14476 Potsdam, Germany

Supporting Information

ABSTRACT: Metal halide perovskites have emerged as materials of high interest for solar energy-to-electricity conversion, and in particular, the use of mixed-ion structures has led to high power conversion efficiencies and improved stability. For this reason, it is important to develop means to obtain atomic level understanding of the photoinduced behavior of these materials including processes such as photoinduced phase separation and ion migration. In this paper, we implement a new methodology combining visible laser illumination of a mixed-ion perovskite ((FAP-

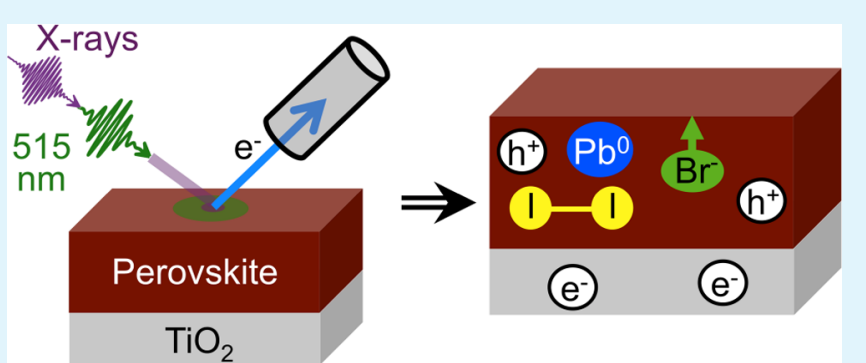
$\left.\left.\mathrm{bI}_{3}\right)_{0.85}\left(\mathrm{MAPbBr}_{3}\right)_{0.15}\right)$ with the element specificity and chemical sensitivity of core-level photoelectron spectroscopy. By carrying out measurements at a synchrotron beamline optimized for low X-ray fluxes, we are able to avoid sample changes due to $\mathrm{X}$-ray illumination and are therefore able to monitor what sample changes are induced by visible illumination only. We find that laser illumination causes partially reversible chemistry in the surface region, including enrichment of bromide at the surface, which could be related to a phase separation into bromide- and iodide-rich phases. We also observe a partially reversible formation of metallic lead in the perovskite structure. These processes occur on the time scale of minutes during illumination. The presented methodology has a large potential for understanding light-induced chemistry in photoactive materials and could specifically be extended to systematically study the impact of morphology and composition on the photostability of metal halide perovskites.

KEYWORDS: photoelectron spectroscopy, laser illumination, lead halide perovskite, ion migration, phase separation, stability

\section{INTRODUCTION}

Perovskite-based solar cells originated in 2009 from liquidelectrolyte-based dye-sensitized solar cells with a power conversion efficiency of $3.8 \%^{1}$ and poor stability. Since then, they have evolved to solid-state devices ${ }^{2,3}$ with much improved stability and over $22 \%$ efficiency. ${ }^{4}$ Reaching such a remarkable level of performance has been possible, partly because of the beneficial optoelectronic properties and benign defects ${ }^{5}$ of the metal halide semiconductors. High absorption coefficients allow for absorber layers as thin as $300 \mathrm{~nm}$, which combined with the long charge carrier diffusion length of about $1 \mu \mathrm{m}$ enable excellent charge collection. ${ }^{6}$

Another important advantage with these materials is their tunability. Mixtures of different cations and anions have been used to tune the optoelectronic properties of the perovskite and to enhance efficiencies and stabilities. In the original $\mathrm{ABX}_{3}$ structure, methylammonium $\left(\mathrm{MA}^{+}\right) \mathrm{CH}_{3} \mathrm{NH}_{3}{ }^{+}$was introduced as the cation at the A site, but more recently, methylammonium has been fully or partially replaced by other cations such as formamidinium $\left(\mathrm{FA}^{+}\right) \mathrm{CH}_{2}\left(\mathrm{NH}_{2}\right)_{2}^{+}$, cesium $\left(\mathrm{Cs}^{+}\right)$, and more recently rubidium $\left.\left(\mathrm{Rb}^{+}\right)\right]^{7-12} \mathrm{~B}$ is typically lead $\left(\mathrm{Pb}^{2+}\right)$ but can be replaced with tin $\left(\mathrm{Sn}^{2+}\right)$ to narrow the band gap, but currently at the cost of stability. Finally, X, which originally was iodide $\left(\mathrm{I}^{-}\right)$, can be fully or partially replaced by, for example,

Received: July 20, 2017

Accepted: September 19, 2017

Published: September 19, 2017 
bromide $\left(\mathrm{Br}^{-}\right)$to further tune the band gap. Typically, in a mixture of $\mathrm{Br}^{-}$and $\mathrm{I}^{-}$, a high iodide content leads to smaller band gaps (from $2.3 \mathrm{eV}$ for $\mathrm{MAPbBr}_{3}$ to $1.6 \mathrm{eV}$ for $\left.\mathrm{MAPbI}_{3}\right)^{13}$ with optimum solar cell efficiencies around $15 \% \mathrm{Br}$ content. $^{14-16}$ Many studies have focused on improving the deposition techniques and the crystal quality of perovskite films, and it was, for example, shown that illumination during film formation can enhance the quality of perovskite films. ${ }^{17}$

Even though perovskite solar cells have improved in stability in recent years, ${ }^{18}$ for example, by moving from $\mathrm{MAPbI}_{3}$ to mixed-ion perovskites, stability still remains an important obstacle for the commercialization of perovskite solar cells. Perovskite solar cells are known to break down by heating, in contact with humidity, and under UV radiation. ${ }^{16,19-22}$ This is not optimal for a solar cell expected to operate under hot and humid conditions and under illumination for over 20 years with little loss of efficiency. In addition to the impact of external factors such as humidity on the solar cell stability, it is also important to understand how the absorber material itself is affected by continued visible-light illumination. For mixedanion perovskites with certain $\mathrm{I}^{-}$and $\mathrm{Br}^{-}$ratios, a reversible photoinduced phase separation into I-rich and Br-rich phases has been observed. ${ }^{23-27}$

Perovskites also suffer from what has been referred to as $\mathrm{JV}$ hysteresis where the output of the cell depends on if it is scanned from short circuit to open circuit or vice versa. ${ }^{28}$ This is believed to be caused by diffusion of ions inside the perovskite under a bias voltage and illumination. ${ }^{29,30}$ The migration of ions is generally believed to be linked to $\mathrm{I}^{-}$ vacancies due to the low activation energy; however, mechanisms including MA have also been suggested. Information on such processes is important, as they may impact the intrinsic stability of metal halide perovskites during solar illumination.

Photoelectron spectroscopy (PES) is a method highly suited to studying chemical changes at the perovskite surface and therefore to investigate the stability and ion movement. PES works by using monochromatized X-rays to eject electrons from core and valence levels in a material. The kinetic energy of these electrons can be experimentally measured, and knowing the photon energy, the binding energy can be calculated using eq 1:

$$
E_{\mathrm{k}}=h \nu-E_{\mathrm{b}}-\phi
$$

where $E_{\mathrm{k}}$ is the kinetic energy of the photoelectron, $\phi$ is the work function of the analyzer, and $E_{\mathrm{b}}$ is the binding energy of the electron. PES allows us not only to determine the elemental composition of a material but also to distinguish different oxidation states and chemical environments for each element in the material. Furthermore, the different peak intensities in conjunction with the photoionization cross sections can be used to determine the relative amounts of the various elements and chemical states. PES is a surface-sensitive technique with the probing depth depending on the kinetic energy of the emitted electrons. By varying the photon energy, the probing depth can therefore be varied for a given core level. We have previously used PES to determine the surface versus bulk chemical compositions of perovskites ${ }^{31,32}$ and to determine the energy alignment with contacting layers in solar cells. ${ }^{33}$ Furthermore, PES is suited for investigating chemical changes that occur at the perovskite surface because of external factors, and we have, for example, studied the impact of humidity and heating on $\mathrm{MAPbI}_{3}{ }^{34}$
A challenge for such measurements can arise through changes of the perovskite, which are caused by the X-rays used for the photoemission experiment. In the traditional leadbased organic perovskite, such processes can be followed by the decrease of the nitrogen signal from the cation and/or the appearance of metallic lead. This is generally observed by consecutive core-level measurements while these effects, although substantial, may be more difficult to follow and quantify by valence-level measurements such as traditional ultraviolet photoelectron spectroscopy. A new opportunity to overcome this challenge is implementing time-of-flight spectrometers instead of using the more traditional hemispherical analyzers. The LowDosePES beamline ${ }^{35}$ at BESSY II is based on this technology and combines a relatively low flux of soft X-ray photons with a highly efficient electron spectrometer. ${ }^{36}$ This system offers much improved opportunities to study X-ray-sensitive systems.

PES using traditional spectrometers has been recently used to investigate the effects of illumination on $\mathrm{MAPbI}_{3}{ }^{37}$ and on $\mathrm{MAPbI}_{3-x} \mathrm{Cl}_{x}{ }^{38}$ In the first case, the degradation of $\mathrm{MAPbI}_{3}$ was observed through a decrease in the amounts of iodide and methylammonium in relation to lead as well as in the formation of metallic lead. In the latter case, substantial formation of metallic lead was also observed for prolonged illumination with white light and was accompanied by a significant decrease in the concentration of iodide and the formation of $\mathrm{PbI}_{2}$.

In this paper, we use the new opportunities with the LowDosePES beamline described above to investigate the changes caused by laser irradiation to the surface of a thin film of a mixed-ion perovskite $\left(\left(\mathrm{FAPbI}_{3}\right)_{0.85}\left(\mathrm{MAPbBr}_{3}\right)_{0.15}\right)$ in detail. This perovskite has given high efficiencies in solar cells, with the record efficiency in our constellation being approximately $18 \%$ when the films are made using an ambient air processing method also employed here. ${ }^{39}$ Using the element specificity and chemical sensitivity of core-level spectroscopy, we are able to follow the chemical changes that occur at the sample surface during illumination. These changes include substantial intensity changes in the amounts of $\mathrm{Br}, \mathrm{I}$, and $\mathrm{Pb}$ and the (partially reversible) formation of metallic lead which will be the focus of the present paper. In contrast to the results of the studies on methylammonium-based perovskites described above, ${ }^{37,38}$ we do not observe a decrease in the overall halide concentration, which would suggest a significant nonreversible degradation of the perovskite. Additionally, corelevel shifts were found during laser illumination, which are consistent with charge separation to the $\mathrm{TiO}_{2}$ substrate.

\section{EXPERIMENTAL METHODS}

Sample Fabrication. Fluorine-doped tin oxide (FTO) glass substrates (Pilkington TEC-15) were cut to dimensions of $14 \times 24$ $\mathrm{mm}^{2}$ and then washed in an ultrasonic bath sequentially in $2 \%$ RBS 50 solution (Fluka) in deionized water, deionized water, acetone, and ethanol, each wash lasting around $30 \mathrm{~min}$. After drying the substrates with dry air, a thin $(50-100 \mathrm{~nm})$ dense $\mathrm{TiO}_{2}$ blocking layer was deposited on the substrates by spray pyrolysis of $0.2 \mathrm{M}$ titanium(IV)tetraisopropoxide (Sigma-Aldrich) and $2 \mathrm{M}$ acetylacetone (SigmaAldrich) in isopropanol (Sigma-Aldrich) at $500{ }^{\circ} \mathrm{C}$. Then, a diluted solution of $\mathrm{TiO}_{2}$ nanoparticle paste (Dyesol DSL 30NR-D) in ethanol $(150 \mathrm{mg} / \mathrm{mL})$ was spin-coated on the substrates at $4000 \mathrm{rpm}$ for $30 \mathrm{~s}$, and the samples were dried on a hot plate at $125{ }^{\circ} \mathrm{C}$ for $15 \mathrm{~min}$, followed by sintering at $500{ }^{\circ} \mathrm{C}$ in air for $30 \mathrm{~min}$.

The perovskite solution consisting of $1.1 \mathrm{M} \mathrm{PbI}_{2}$ (TCI Chemicals), $0.2 \mathrm{M} \mathrm{PbBr}_{2}$ (Alfa Aesar), $1 \mathrm{M}$ formamidinium iodide (Dyenamo), and 0.2 M MABr (Dyenamo) in 4:1 dimethylformamide/dimethylsulf- 


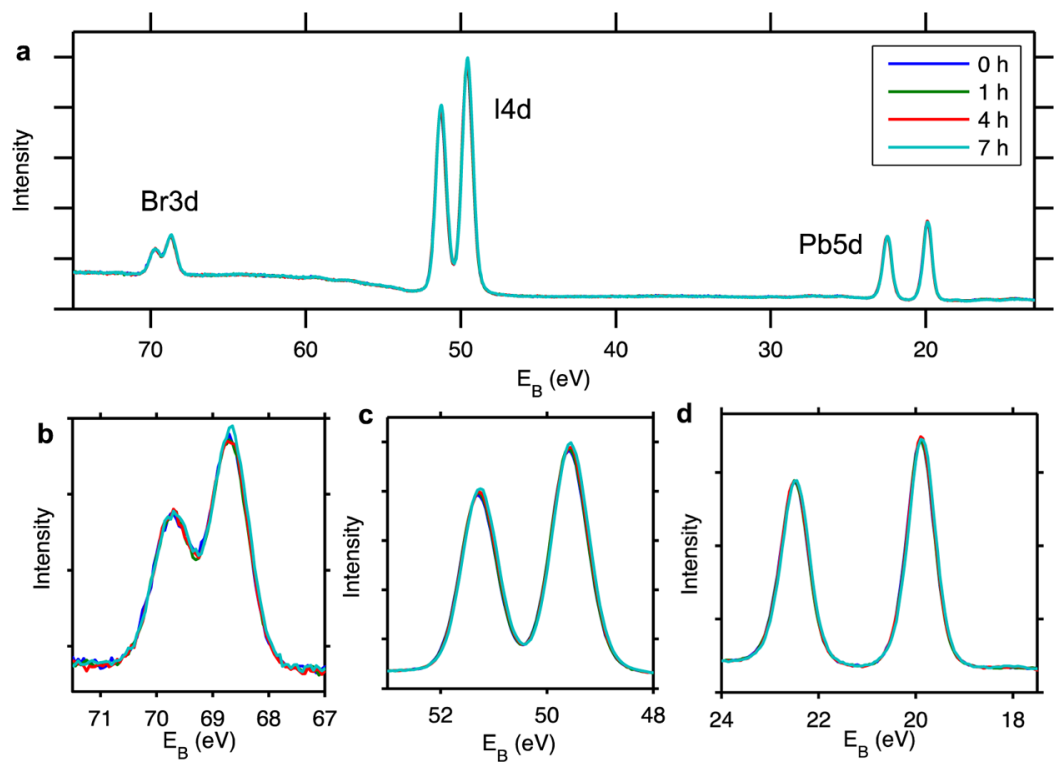

Figure 1. Stability of perovskite samples under X-ray irradiation at the LowDosePES beamline. Spectra at selected times $(0,1,4$, and $7 \mathrm{~h})$ measured during $7 \mathrm{~h}$ of continuous X-ray irradiation in the same spot of a mixed-cation perovskite sample with a photon energy of $139 \mathrm{eV}$. (a) Total spectral region. (b) Zoom-on Br 3d peaks. (c) Zoom-on I 4d peaks. (d) Zoom-on Pb 5d peaks.

oxide (both from Sigma-Aldrich) was prepared in an argon-filled glovebox by heating to around $100{ }^{\circ} \mathrm{C}$ to dissolve the inorganic salts (otherwise kept at room temperature). The perovskite films were prepared in ambient conditions ${ }^{39}$ by preheating the substrate (mesoporous $\mathrm{TiO}_{2}$ film and dense $\mathrm{TiO}_{2}$ on conductive glass) on a hot plate at $60^{\circ} \mathrm{C}$ and spin-coating $75 \mu \mathrm{L}$ of perovskite solution on the warm substrate with a program of $1000 \mathrm{rpm}$ for $10 \mathrm{~s}$ and $4000 \mathrm{rpm}$ for $30 \mathrm{~s}$. In the middle of the second step (at $15 \mathrm{~s}$ ), $150 \mu \mathrm{L}$ of antisolvent chlorobenzene (Sigma-Aldrich) was applied on the perovskite layer. After that, the substrates were heated at $100{ }^{\circ} \mathrm{C}$ for $60 \mathrm{~min}$ in air. The resulting perovskite has a band gap of about $1.57 \mathrm{eV}$ as determined previously. ${ }^{39}$

PM4 Beamline. PES measurements were carried out at the LowDosePES endstation $^{35}$ of the PM4 beamline at the synchrotron BESSY II. The endstation is equipped with an angular-resolved timeof-flight (ARTOF-2) spectrometer as well as a hemispherical SES100 analyzer. The ARTOF spectrometer was used for all measurements with the laser, whereas the hemispherical analyzer was used for the quantification of measurements at a higher kinetic energy $(\mathrm{Br} 3 \mathrm{~d}$, I 4d, and $\mathrm{Pb} 5 \mathrm{~d}$ with $540 \mathrm{eV}$ ) to achieve a higher energy resolution. The beamline was operated in pseudo-single bunch mode, where only the camshaft bunch of the BESSY II fill pattern-isolated via a mechanical chopper ${ }^{35,40}$-is used to irradiate the sample. With the selected beamline settings $(360 \mathrm{l} / \mathrm{mm}$ grating and $\mathrm{cff}=1.6)$, X-ray photon fluxes were below $10^{9}$ photons/s at all used energies. Despite the relatively low flux, measurement times were reasonably short thanks to the high transmission of the ARTOF-2 featuring a whole acceptance cone of $\pm 15^{\circ}$. PES measurements were carried out at pressures of around $10^{-9} \mathrm{mbar}$, and ex situ prepared perovskite samples were transferred into the main analysis chamber via a loadlock and a radial distribution chamber.

For photoinduced measurements, the laser system installed at the beamline (Tangerine model from the company Amplitude Systemes) was used at its second harmonic $(515 \mathrm{~nm})$, a pulse length of about 350 fs, and a repetition frequency of $208.33 \mathrm{kHz}$ (i.e., $1 / 6$ of the repetition rate of the synchrotron pulses).

The spatial overlap between the laser and X-ray pulses was regularly checked using an yttrium aluminum garnet (YAG) crystal installed on the manipulator and optimized by moving the piezoactuated laser incoupling mirror. The area of the laser spot was estimated from the YAG crystal to be about $0.046 \mathrm{~mm}^{2}$. The power was adjusted by changing the efficiency of the external acousto-optic modulator of the laser system and was measured using a thermopile-based power sensor right before the in-vacuum laser incoupling optics. The laser powers used here were $1.3,0.52,0.21$, and $0.13 \mathrm{~mW}$, which given the estimated laser spot size correspond to $2800,1100,450$, and $280 \mathrm{~mW} /$ $\mathrm{cm}^{2}$, respectively. Because of the uncertainty in the determination of the exact power density in the overlap area of the laser and X-ray spots, we quote the measured laser powers in milliwatts throughout the paper.

Measurements with Laser. Measurements with the laser were carried out on fresh sample spots. Prior to and after each laser exposure, the spot was analyzed by an overview spectrum taken with the same photon energy as the measurements with laser illumination. Measurements with the laser were then carried out with the ARTOF spectrometer in a fixed mode and the kinetic energy window centered on the core level of interest. Each of these measurements was started with the laser shuttered. Then, usually after $5 \mathrm{~min}$, the laser shutter was opened and the measurement was continued for the desired duration with both laser and X-rays illuminating the same sample spot. Finally, the laser was shuttered again, and the measurement was continued for some time.

Data Analysis. The spectra measured with the ARTOF were analyzed using the IGOR ARTOF loader and analysis package available at the endstation to convert the raw data into spectra of intensity versus kinetic energy. As no angular dependence was observed, all spectra presented here were integrated over the entire acceptance cone of the electron spectrometer. The spectra were calibrated by measuring the Fermi level or the Au $4 \mathrm{f}$ level of a gold foil mounted on the manipulator. The binding energy of the Au $4 f_{7 / 2}$ level was set to $84 \mathrm{eV}$.

For the measurements with the laser, the spectra were loaded as a series of bins, each of $30 \mathrm{~s}$ size ( $60 \mathrm{~s}$ for the $\mathrm{Br} 3 \mathrm{~d}$ core level), to give a matrix of intensity $(z)$ versus binding energy $(x)$ and time $(y)$. After energy calibration, this matrix was exported to MATLAB for further analysis. The spectra at each time point were fitted with a series of Gaussian functions representing the number of peaks present in the spectra and a quadratic background. For the fit of the $\mathrm{Pb} 5 \mathrm{~d}$ spectra, four Gaussian peaks were used, representing two spin-orbit doublets $\left(\mathrm{Pb}^{2+}\right.$ and $\left.\mathrm{Pb}^{0}\right)$. The relative intensity and separation of the $\mathrm{Pb}^{0}$ doublet were fixed to those of the $\mathrm{Pb}^{2+}$ doublet. For I $4 \mathrm{~d}$ and $\mathrm{Br} 3 \mathrm{~d}$, only one spin-orbit doublet was used for fitting. From the fitted parameters, the relative changes in peak positions and intensities (i.e., in the integrated area of the peaks) could be determined. For Pb $5 \mathrm{~d}$, also the percentage of $\mathrm{Pb}^{0}$, which was formed, was estimated according to intensity $\left(\mathrm{Pb}^{0}\right) /\left[\right.$ intensity $\left(\mathrm{Pb}^{0}\right)+$ intensity $\left.\left(\mathrm{Pb}^{2+}\right)\right] \times 100$. All 
spectra and fit results were normalized to the background of the spectra to account for intensity variations in the single bunch current of the synchrotron.

\section{RESULTS}

Stability upon X-ray Exposure. PES can be used to determine the elemental composition of sample surfaces and therefore to confirm their quality. The steady-state photoelectron spectra of the MAFA perovskite can be found in Figures 1, S1, and S2. Quantification was carried out on the $\mathrm{Br}$ $3 \mathrm{~d}, \mathrm{I} 4 \mathrm{~d}$, and $\mathrm{Pb} 4 \mathrm{~d}$ peaks measured at a photon energy of 540 $\mathrm{eV}$ (Figure $\mathrm{S} 1$ ) and showed $\mathrm{Br} / \mathrm{Pb}$ and $\mathrm{I} / \mathrm{Pb}$ ratios in good agreement with the nominal sample composition (Table 1).

Table 1. Relative Intensities of $\mathrm{Pb}, \mathrm{I}$, and $\mathrm{Br}^{a}$

$\begin{array}{lcccc} & \begin{array}{c}\text { relative } \\ \text { intensity } \\ \text { (theoretical) }\end{array} & \begin{array}{c}\text { relative intensity } \\ \text { (experimental) }\end{array} & \begin{array}{c}\text { normalized } \\ \text { intensity } \\ \text { (laser off) }\end{array} & \begin{array}{c}\text { relative } \\ \text { intensity } \\ \text { (laser off) }\end{array} \\ \mathrm{Pb} & 1 & 1 & 0.89 & 0.89 \\ \mathrm{I} & 2.55 & 2.56 & 0.91 & 2.32 \\ \mathrm{Br} & 0.45 & 0.44 & 1.92 & 0.86\end{array}$

${ }^{a}$ Theoretical (from preparation) and experimental (from PES with a photon energy of $540 \mathrm{eV}$ ) values before laser illumination. The third column shows the values after $30 \mathrm{~min}$ of $0.52 \mathrm{~mW}$ laser illumination, normalized to the corresponding intensity before illumination. The fourth column shows the estimated amounts in the surface region compared to the theoretical ratios before illumination (calculated by multiplying the values in column 1 and 3 ). An increase of the relative amount of halides relative to $\mathrm{Pb}$ is found.

Analysis of the $\mathrm{N} 1 \mathrm{~s}$ region can be used to compare the amount of MA and FA in the samples, as the nitrogen peaks for MA and FA appear at distinctly different binding energies. ${ }^{31}$ A ratio of $\mathrm{MA} / \mathrm{FA}=30: 70$ was found for our sample, which is slightly higher than the nominal ratio of 15:85 and could be related to variations of the distribution close to the sample surface as discussed previously. ${ }^{31}$ Similar information can, in principle, be obtained from C 1s, but the analysis of this core level is more complicated because of the presence of carbon contamination on the surface of an ex situ prepared sample (Figure S2). As discussed above, a concern for PES measurements of perovskites arises because of the instability of the materials under high X-ray flux. As shown in Figure 1, this is not a concern with the low X-ray flux at the LowDose beamline: during $7 \mathrm{~h}$ of continuous X-ray illumination on the same spot, no significant changes were observed in the perovskite peak positions and intensities, with variations in the peak positions being less than $0.05 \mathrm{eV}$ during this time. Furthermore, the $\mathrm{Br}$ $3 \mathrm{~d}, \mathrm{I} 4 \mathrm{~d}$, and $\mathrm{Pb} 5 \mathrm{~d}$ peaks are observed at similar binding energies as previously observed for a similar sample on a $\mathrm{TiO}_{2}$ substrate. ${ }^{31}$ Therefore, in the following, any effects linked to the influence of X-rays, such as sample degradation or sample charging, can be disregarded.

Effects of Visible $(515 \mathrm{~nm})$ Illumination. $\mathrm{Pb} 5 \mathrm{~d}$. Figure 2 shows a typical evolution of the $\mathrm{Pb} 5 \mathrm{~d}$ core-level spectra of the perovskite during laser illumination. Before laser illumination, only a single spin-orbit doublet is observed. This doublet is assigned to the perovskite and will be referred to as $\mathrm{Pb}^{2+}$. Upon switching the laser on, the doublet shifts to higher binding energies by approximately $0.1 \mathrm{eV}$. During laser illumination, the intensity of the doublet slowly decreases while a new doublet, which can be assigned to the formation of metallic lead, $\mathrm{Pb}^{0}$, appears at lower binding energies and increases with time. Upon switching the laser off, $\mathrm{Pb}^{2+}$ shifts to lower binding energies again and the intensity of $\mathrm{Pb}^{0}$ decreases with time. We also measured the changes in the $\mathrm{Pb} 5 \mathrm{~d}$ spectra with lower and higher laser intensities (Figure S3), and similar changes were observed. To quantify the variations and compare the effect of different light intensities, we fitted the individual spectra with Gaussian peaks representing the two spin-orbit split doublets connected to the different oxidation states of $\mathrm{Pb}$. Examples of these fits are shown in Figure $2 b$, for a spectrum before laser illumination, for a spectrum during laser illumination, and for a spectrum after laser illumination. From the results of these fits, we work out the change in intensity of the total amount of lead $\left(\mathrm{Pb}^{0}+\mathrm{Pb}^{2+}\right.$; Figure $\left.3 \mathrm{a}\right)$, the percentage of metallic lead (Figure $3 \mathrm{~b}$ ), and the change in the $\mathrm{Pb}^{2+}$ peak position (Figure $3 \mathrm{c}$ ). It can be seen that the total amount of $\mathrm{Pb}$ observed decreases
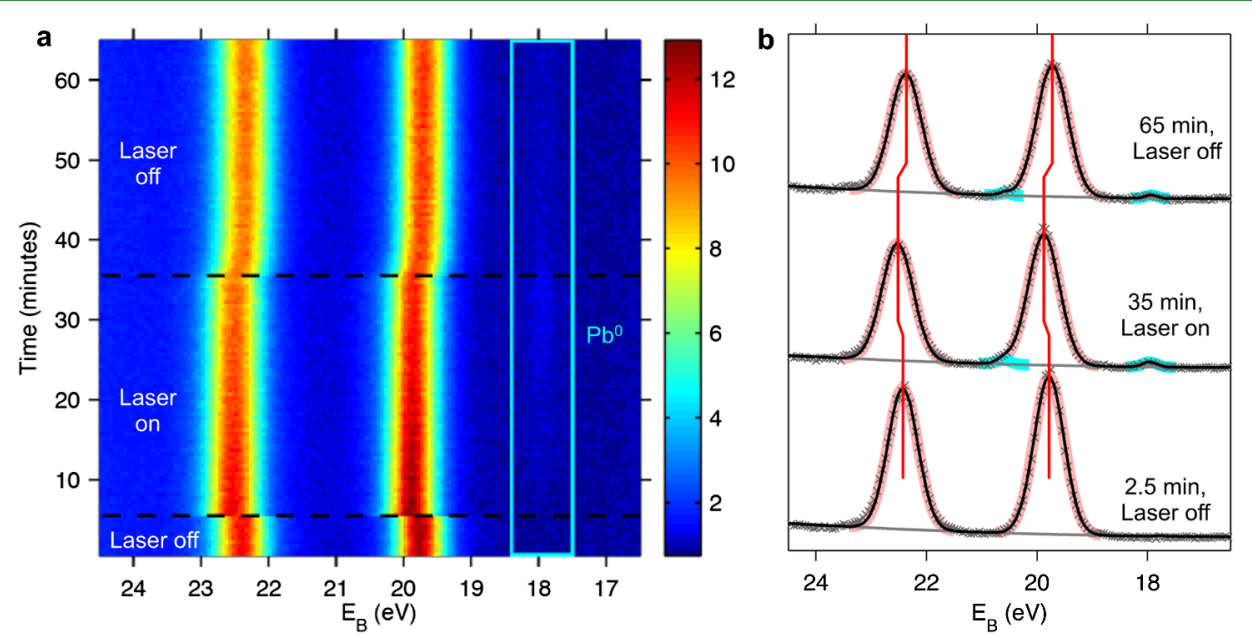

Figure 2. Time evolution of the $\mathrm{Pb} 5 \mathrm{~d}$ spectra measured with a photon energy of $90 \mathrm{eV}$ before, during, and after laser illumination at $515 \mathrm{~nm}$ and a power of $0.52 \mathrm{~mW}$. (a) Normalized intensity of spectra vs binding energy and time. The black horizontal lines indicate where the laser was switched on $(5 \mathrm{~min})$ and off $\left(35 \mathrm{~min}\right.$ ). The region where a signal due to $\mathrm{Pb}^{0}$ appears during laser illumination is highlighted. (b) Pb $5 \mathrm{~d}$ spectra (gray crosses) at selected times: $2.5 \mathrm{~min}$ (laser off), $35 \mathrm{~min}$ (laser on), and $65 \mathrm{~min}$ (laser off). The total fit is shown as a solid black line, and the quadratic background is shown as a gray line for each spectrum. The Gaussian doublet for $\mathrm{Pb}^{2+}$ is shown in light red, and the doublet for $\mathrm{Pb}^{0}$ is shown in cyan. The vertical red lines indicate the changes in the $\mathrm{Pb}^{2+}$ peak position between the different spectra. 

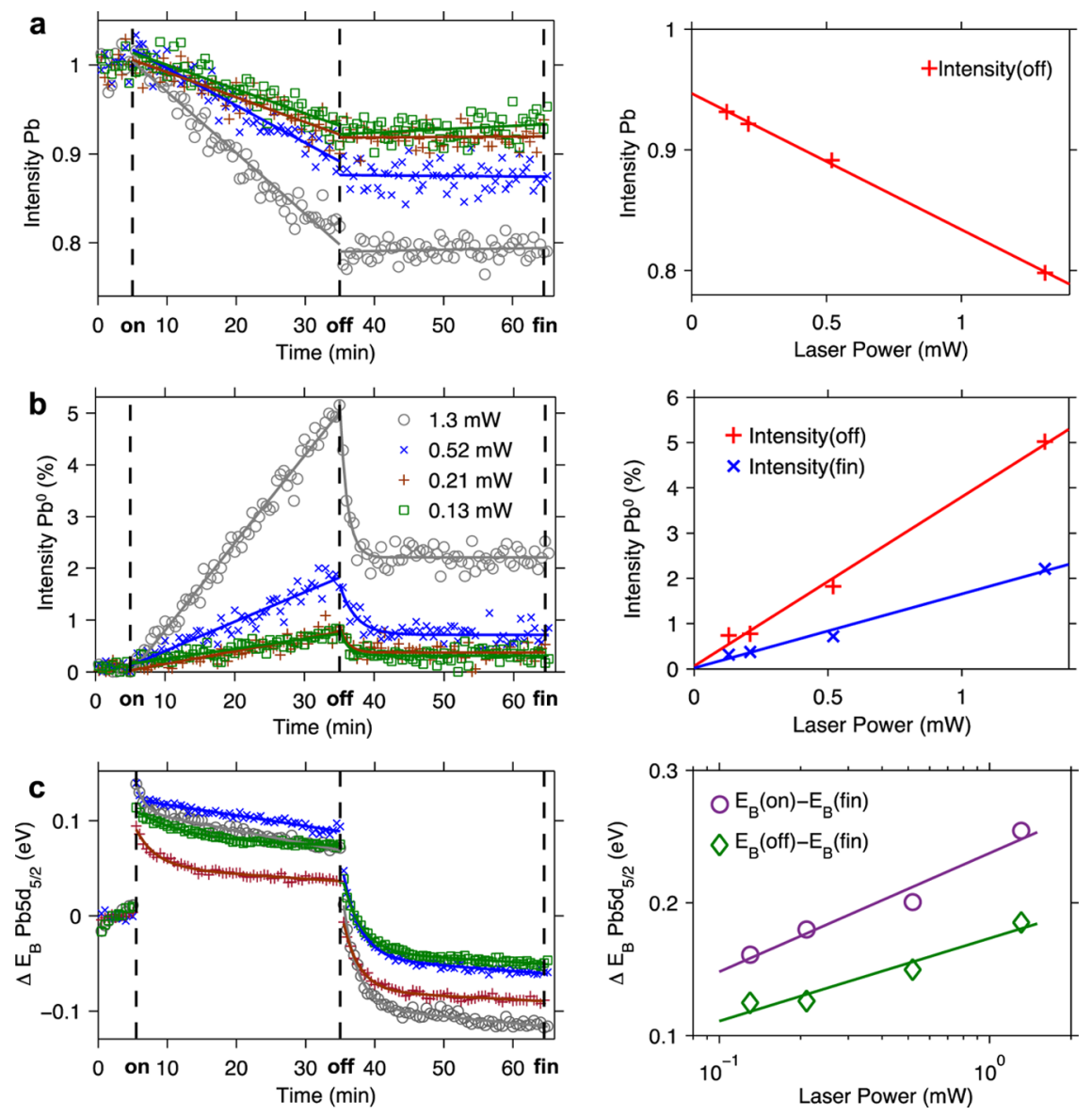

Figure 3. Laser power dependence of fit parameters of the $\mathrm{Pb} 5 \mathrm{~d}$ spectra. (a) Total intensity of $\mathrm{Pb} 5 \mathrm{~d}\left(\mathrm{~Pb}^{2+}\right.$ and $\left.\mathrm{Pb}^{0}\right)$ normalized to the intensity before laser illumination. Linear trend lines are included during and after laser illumination as separate trend lines. Right: intensities extracted from the linear fits at the time when the laser was switched off vs the laser power (linear trend line included). (b) Intensity of $\mathrm{Pb}^{0}$ as a percentage of the total $\mathrm{Pb}$ intensity. A linear trend line is included during laser illumination, and a fit to a single exponential decay is made after laser illumination. Right: intensity of $\mathrm{Pb}^{0}$ at the time the laser was switched off (red) and intensity of $\mathrm{Pb}^{0}$ after the exponential decay (blue) vs laser power, with linear trend lines included. (c) Change in the $\mathrm{Pb}^{2+} 5 \mathrm{~d}_{5 / 2}$ position relative to the average $\mathrm{Pb}^{2+} 5 \mathrm{~d}_{5 / 2}$ position before laser illumination. The data are fitted to the sum of an exponential and a straight line. Right: difference between the $\mathrm{Pb}^{2+} 5 \mathrm{~d}_{5 / 2}$ position just after the laser was switched on and the position in the final spectrum (purple) as well as the difference between the position just before the laser was switched off and the position in final spectrum (green) vs laser power. Note that the laser power is plotted on a log scale in this case. Linear trend lines are included.

during laser illumination and remains at the lower amount after the laser is switched off, with a larger decrease observed for higher laser powers. $\mathrm{Pb}^{0}$ appears during laser illumination and increases linearly for all laser intensities, with a higher gradient and a higher final concentration for higher intensities. Upon switching the laser off, the amount of $\mathrm{Pb}^{0}$ decreases in the first few minutes and then a constant amount of $\mathrm{Pb}^{0}$ is reached for all laser powers. The final amount of $\mathrm{Pb}^{0}$ after switching of the laser is approximately $44 \%$ of the amount measured immediately before the laser is switched off.

The change in the $\mathrm{Pb}^{2+}$ peak position follows the same pattern for the different laser powers: an initial shift to higher binding energies by about $0.1 \mathrm{eV}$, followed by a slow change in position back to lower binding energies during illumination, and a change to lower binding energies upon switching the laser off, followed by a further decrease (Figure 3c). The magnitude of the initial shift does not show a trend with regard to laser power. However, comparing the final peak position (last point in Figure $3 \mathrm{c}$ on the left) with the peak position just after switching the laser on and the peak position just before switching the laser off, a trend with laser power can be observed: the change in peak position increases with laser power (Figure 3c).

I $4 d$ and $\mathrm{Br} 3 d$. Figure 4 shows the laser measurements of I $4 \mathrm{~d}$ and $\mathrm{Br} 3 \mathrm{~d}$ core levels with the same laser power as the data presented for the $\mathrm{Pb} 5 \mathrm{~d}$ core level in Figure 1. The spectra were measured with photon energies of 120 and $139 \mathrm{eV}$ so that the kinetic energies of the photoelectrons were roughly the same for $\mathrm{Pb} \mathrm{5d}, \mathrm{I} 4 \mathrm{~d}$, and $\mathrm{Br} 3 \mathrm{~d}$ (approximately $65 \mathrm{eV}$ ). This ensures that the elements are probed with a very similar mean free path of emitted electrons, that is, a very similar surface sensitivity. For both I $4 \mathrm{~d}$ and $\mathrm{Br} 3 \mathrm{~d}$, only one spin doublet component is observed before, during, and after laser illumination. The spectra were therefore fitted with two Gaussian peaks representing a single chemical species for each element. Figure $4 \mathrm{c}, \mathrm{d}$ shows the normalized intensity and relative position of the I $4 \mathrm{~d}_{5 / 2}$ and the $\mathrm{Br} 3 \mathrm{~d}_{5 / 2}$ peaks compared to those of $\mathrm{Pb} 5 \mathrm{~d}$. It can be seen that the intensity of I $4 \mathrm{~d}$ also decreases during laser illumination but increases again after the laser is switched off. The intensity of $\mathrm{Br} 3 \mathrm{~d}$ increases significantly during laser illumination and decreases as the laser is switched off. The peak positions for all three elements shift in a comparable way during and after laser illumination (Figure 4d). 

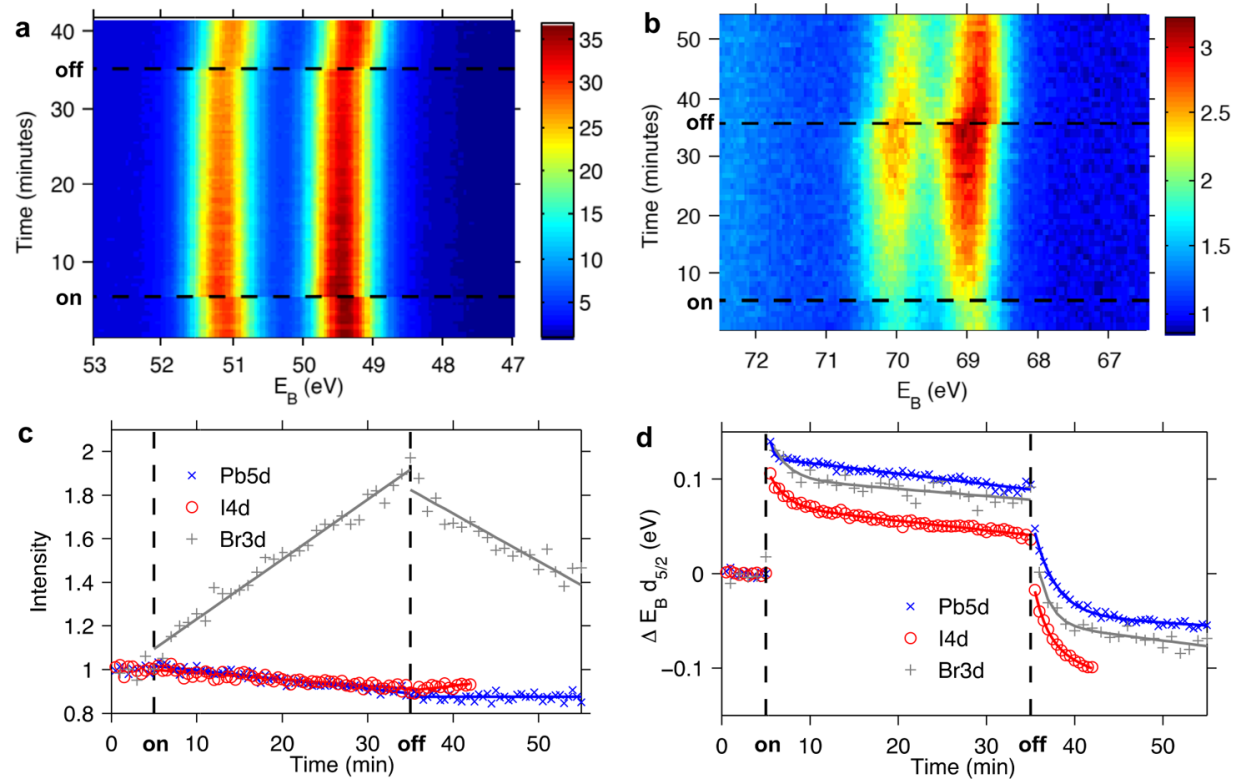

Figure 4. Time evolution of the I $4 \mathrm{~d}$ spectra measured with a photon energy of $120 \mathrm{eV}$ (a) and $\mathrm{Br} 3 \mathrm{~d}$ spectra measured with a photon energy of 139 $\mathrm{eV}$ (b) before, during, and after laser illumination at $515 \mathrm{~nm}$ and a power of $0.52 \mathrm{~mW}$. The black horizontal lines indicate where the laser was switched on $(5 \mathrm{~min})$ and off $(35 \mathrm{~min})$. Only one spin doublet is seen in each case, indicating that no formation of new I and Br species is observed in the solid state. (c) Comparison of the intensities of $\mathrm{Pb} 5 \mathrm{~d}, \mathrm{I} 4 \mathrm{~d}$, and $\mathrm{Br} 3 \mathrm{~d}$ vs time obtained by fitting the individual spectra. The intensities are normalized to the intensity before laser illumination for each core level. Linear fit lines are included during and after laser illumination. (d) Changes in the $d_{5 / 2}$ peak positions relative to the average positions before laser illumination. Fitted lines $(1$ exponential + linear $)$ are included.

Using the nominal relative amounts of $\mathrm{Pb}, \mathrm{I}$, and $\mathrm{Br}$ in the samples and the intensity changes determined from the measurements with the laser, we can work out the relative amounts after $30 \mathrm{~min}$ of laser illumination (Table 1). These values suggest that there is an increase in bromide concentration, which is not completely balanced with the decrease in iodide concentration during illumination, and an overall increase in the halide $\left(\mathrm{I}^{-}+\mathrm{Br}^{-}\right)$concentration can be observed.

$N$ 1s. We also investigated the effect of laser illumination on the $\mathrm{N}$ 1s spectra by the measurement of these spectra in spots that had been illuminated by the laser and in a fresh spot on the sample with a photon energy of $540 \mathrm{eV}$ (Figure S2). The measurement of $\mathrm{N}$ 1s spectra with good statistics takes significantly longer than the measurement of $\mathrm{Pb} 5 \mathrm{~d}, \mathrm{I} 4 \mathrm{~d}$, and $\mathrm{Br} 3 \mathrm{~d}$ because of the lower cross section of $\mathrm{N}$ 1s and the lower photon flux at higher photon energies at the PM4 beamline. ${ }^{35}$ Therefore, it was not possible to investigate the changes in the $\mathrm{N}$ 1s spectra during laser illumination. However, the measurement of $\mathrm{N} 1 \mathrm{~s}$ in sample spots that had been illuminated by the laser showed no significant intensity difference as compared to the spectrum from a fresh spot.

\section{DISCUSSION}

The chemical changes observed here are clearly induced by the visible laser illumination. Our control experiment in which the $\mathrm{X}$-ray illumination was switched off during laser illumination shows that the presence of X-ray photons did not alter the observed effect and only the visible laser light is needed to induce changes (Figure 1 and the Supporting Information). Furthermore, the effects observed are not consistent with the decomposition of the material due to heating ${ }^{34}$ because this would be expected to result in a significant decrease in the nitrogen intensity. Moreover, the observed intensity changes vary linearly with laser power and therefore photon flux.
Together, these findings clearly suggest that the changes are due to photoinduced reactions.

For the amount of $\mathrm{Pb}^{0}$, a linear trend with the total number of photons was found (Figure 5). These data were extracted

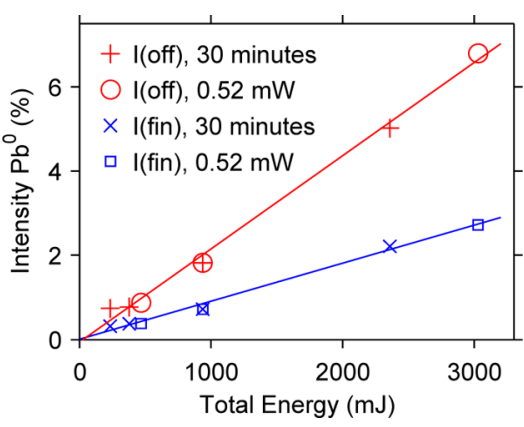

Figure 5. Intensity of metallic lead at the end of illumination [I(off) and $30 \mathrm{~min}$ after illumination $\mathrm{I}(\mathrm{fin})$ ] vs total illumination energy (laser power $\times$ illumination time) determined from 30 min illumination experiments at different laser powers and from experiments with 0.52 $\mathrm{mW}$ for different illumination times.

from the resulting concentrations as a function of total illumination either by using different laser powers during 30 min or by using different illumination times but at a constant laser power of $0.52 \mathrm{~mW}$ (Figure S4).

The immediate change observed for the core-level peak positions upon switching on the laser is consistent with the generation of a photovoltage between the $\mathrm{FTO} / \mathrm{TiO}_{2}$ substrate and the perovskite absorber. Illumination should lead to electron injection into the substrate, creating a voltage drop and electric field somewhere between the substrate and the surface, and therefore to a splitting of the Fermi levels (Figure 6a). As the PES measurements are referenced to the Fermi level of the substrate, which is in direct electrical contact with the ground of 

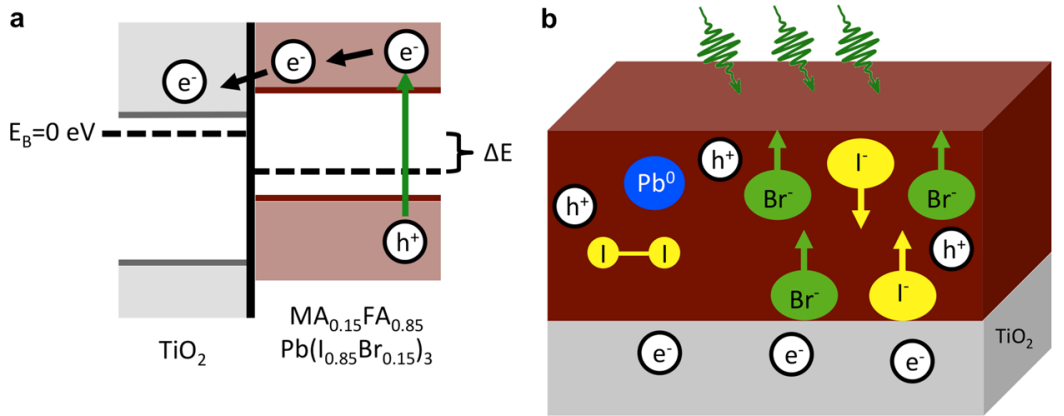

Figure 6. (a) Illumination leading to charge separation to the substrate and a change in Fermi levels. (b) Schematic image of the composition changes in the perovskite film under illumination: $\mathrm{Pb}^{0}$ and $\mathrm{I}_{2}$ are formed. The surface becomes more halide-rich. $\mathrm{Br}^{-}$moves to the surface.

the spectrometer, this leads to a shift of the perovskite core levels to more positive binding energies. As the perovskite surface region becomes positively charged because of the charge separation, more energy is required to photoemit its electrons. This interpretation is further supported by preliminary results of a perovskite on a p-type $\mathrm{NiO}_{x}$ substrate, where the peaks are at lower binding energies during illumination compared to those under dark conditions, consistent with the accumulation of electrons in the perovskite film. For the $\mathrm{FTO} / \mathrm{TiO}_{2} /$ perovskite sample studied here, the changes in peak position upon following from continuous illumination indicate that the Fermi level splitting is followed by slower chemical changes. The shift back to more negative binding energies upon switching the laser off is consistent with a recombination of charges and a re-establishment of the equilibrium of the Fermi level of the perovskite and the substrate. The slow changes in peak position during and after laser illumination are likely to be related to the changing chemistry of the perovskite surface as will be discussed below.

The changes in the $\mathrm{Pb}^{2+}, \mathrm{I}^{-}$, and $\mathrm{Br}^{-}$concentrations and the formation of $\mathrm{Pb}^{0}$ observed here are likely due to a combination of effects, and a summary of our suggested mechanisms is shown in Figure 6b. The increase of $\mathrm{Br}^{-}$relative to $\mathrm{I}^{-}$and $\mathrm{Pb}^{2+}$ suggests the formation of a Br-rich phase at the surface upon illumination. The direction of the field caused by electron injection and accumulation in $\mathrm{TiO}_{2}$ with a positive potential at the perovskite/vacuum interface may initialize ion migration, leading to an increased overall halide concentration at the surface (Table 1). Reduction of the perovskite to $\mathrm{Pb}^{0}$ has to occur in a photoinduced electron-transfer reaction. In the excitation of the perovskite material with $515 \mathrm{~nm}$ photons, electron density is transferred from the highest valence levels, which largely consist of I 5p orbitals, to the lowest conduction band levels, which are largely associated with $\mathrm{Pb} 6 \mathrm{p}$, the same orbitals, which become partially occupied in $\mathrm{Pb}^{0.41}$ The formation of $\mathrm{Pb}^{0}$ is therefore likely to be initialized by an electron-transfer reaction between $\mathrm{I}^{-}$and $\mathrm{Pb}^{2+}$, and we suggest that the process is followed by the following reaction

$$
\mathrm{FAPbI}_{3}+\text { light } \rightarrow \mathrm{Pb}+\mathrm{I}_{2}+\mathrm{FAI}
$$

In the outermost surface layer, which is probed by PES, any $\mathrm{I}_{2}$, which is formed, is likely to leave the film through sublimation and is therefore not detected in our PES measurements. This mechanism is consistent with a small decrease of $\mathrm{I}^{-}$and $\mathrm{Pb}^{2+}$ in the surface region of the perovskite on the same order of magnitude as the amount of $\mathrm{Pb}^{0}$, which is formed. However, an additional mechanism is needed to explain the larger intensity changes observed for $\mathrm{I}^{-}$and $\mathrm{Br}^{-}$.
Here, we suggest a phase separation with a reversible formation of a $\mathrm{Br}$-rich phase at the sample surface, where some $\mathrm{I}^{-}$ions are replaced by $\mathrm{Br}^{-}$so that the $\mathrm{Br}^{-}$intensity is increased in the surface region and the $\mathrm{I}^{-}$intensity is reduced (Figure $6 \mathrm{~b}$ ). Such effects have been previously observed in photoluminescence measurements of mixed $\mathrm{Br} / \mathrm{I}$ perovskites. ${ }^{23,24}$ Here, the formation of a Br-rich phase appears to occur at the sample surface, which could indicate that it is the grain boundaries that become enriched in $\mathrm{Br}$.

The intensity changes observed here are not consistent with the formation of $\mathrm{PbI}_{2}, \mathrm{PbBr}_{2}$, and volatile $\mathrm{MA}$ or FA fragments, as such processes should lead to an increase in $\mathrm{Pb}$ relative to $\mathrm{I}^{-}$ and $\mathrm{Br}^{-}$. This is further supported as neither a color change nor a decrease in the $\mathrm{N}$ 1s intensity was observed in the illuminated areas, as is common when $\mathrm{PbI}_{2}$ and $\mathrm{PbBr}_{2}$ are formed through heating or exposure to water vapors. ${ }^{34}$ Our results for $\left(\mathrm{FAPbI}_{3}\right)_{0.85}\left(\mathrm{MAPbBr}_{3}\right)_{0.15}$ are therefore very different from those obtained in photoinduced PES studies of $\mathrm{MAPbI}_{3}$ and $\mathrm{MAPbI}_{3-x} \mathrm{Cl}_{x}$, where a degradation of the perovskite and formation of $\mathrm{PbI}_{2}$ and much larger amounts of $\mathrm{Pb}^{0}$ were observed. $^{37,38}$ In our measurements, we therefore observe a better stability of $\left(\mathrm{FAPbI}_{3}\right)_{0.85}\left(\mathrm{MAPbBr}_{3}\right)_{0.15}$ than what others have observed for $\mathrm{MAPbI}_{3}$. At the same time, our results indicate a process linked to a phase separation.

Upon switching off the laser, the core-level peak positions decrease and reach lower binding energies than the original ones, consistent with a decay of the photovoltage and a change in the Fermi level of the perovskite due to the changed composition at the surface. The amount of $\mathrm{Pb}^{0}$ observed decreases again within a few minutes (Figure 3), suggesting that the material at least partially recovers from the changes induced by illumination. The decrease of $\mathrm{Pb}^{0}$ could be due to the migration of $\mathrm{Pb}^{0}$ into the film. Deeper in the film, any $\mathrm{I}_{2}$ formed might remain in the film, leading to the re-formation of the perovskite in the dark

$$
\mathrm{Pb}+\mathrm{I}_{2}+\mathrm{FAI} \rightarrow \mathrm{FAPbI}_{3}
$$

The part of the process, which is not reversible, may therefore be related to the measurement of a bare perovskite surface in ultrahigh vacuum, as the above reaction might always occur if there is no sublimation of $\mathrm{I}_{2}$.

The concentrations of $\mathrm{I}^{-}$and $\mathrm{Br}^{-}$immediately start reversing back toward their original concentrations (Figure 4), suggesting that any induced phase separation is likely to be at least partially reversible. The ion movements observed here could be related to the hysteresis observed in current-voltage measurementsthe correlation of such effects will be the focus of future studies. 


\section{CONCLUSIONS}

In this paper, we have demonstrated a new methodology, which can be used to follow photoinduced chemical changes in materials at an atomic level by combining PES measurements with visible laser illumination. The methodology avoids X-rayinduced effect by the use of low X-ray density at the LowDose photoemission beamline and allowed us to separate visiblelight-induced changes from any X-ray-induced changes, which generally is a severe concern when measuring at other beamlines. The use of an ARTOF spectrometer allowed for the efficient measurement of $\mathrm{Pb}, \mathrm{I}$, and $\mathrm{Br}$ core levels with a high energy resolution.

For the particular mixed perovskite material studied here, we find partially reversible changes occurring during illumination, some of which are clearly caused by the movement of halide ions: during illumination, the concentrations of $\mathrm{I}^{-}$and $\mathrm{Pb}^{2+}$ at the surface decrease while the concentration of $\mathrm{Br}^{-}$increases significantly. This suggests a phase separation with the formation of a Br-rich phase at the surface during illumination, which is reversed in the dark. Furthermore, we observe the partially reversible formation of $\mathrm{Pb}^{0}$, for which we suggest a photoinduced electron-transfer mechanism from $\mathrm{I}^{-}$to $\mathrm{Pb}^{2+}$. Finally, illumination also causes a systematic core-level shift, which we relate to a photovoltage between the perovskite and the $\mathrm{TiO}_{2}$ substrate. With our method, we were therefore able to unravel the details of chemical changes occurring in a mixed-ion perovskite during illumination. While our measurements clearly confirm that illumination leads to ion migration and photoinduced electron-transfer reactions, the partial reversibility of the induced changes also indicates some "self-healing" ability of the perovskite material.

In the future, this method could be extended to a range of photoactive materials including the study of perovskites with a systematic variation in composition and/or crystal quality. The findings from photoinduced PES measurements could then be directly related to device performance and stability, and fundamental limitations to solar cell stability could be identified. Furthermore, the impact of different device configurations such as selective contacts could be investigated.

\section{ASSOCIATED CONTENT}

\section{S Supporting Information}

The Supporting Information is available free of charge on the ACS Publications website at DOI: 10.1021/acsami.7b10643.

Steady-state photoelectron spectra and time evolution of the $\mathrm{Pb} 5 \mathrm{~d}$ core-level spectra for different laser powers and illumination times and in the absence of X-rays during laser illumination (PDF)

\section{AUTHOR INFORMATION}

\section{Corresponding Authors}

*E-mail: ute.cappel@physics.uu.se (U.B.C.).

*E-mail: hakan.rensmo@physics.uu.se (H.R.).

\section{ORCID}

Ute B. Cappel: 0000-0002-9432-3112

Fredrik O. L. Johansson: 0000-0002-6471-1093

Bertrand Philippe: 0000-0003-2412-8503

Gerrit Boschloo: 0000-0002-8249-1469

Andreas Lindblad: 0000-0002-9188-9604

\section{Notes}

The authors declare no competing financial interest.

\section{ACKNOWLEDGMENTS}

The research has received funding from the European Research Council under the European Union's Seventh Framework Programme (FP7/2007-2013)/ERC grant agreement no. [321319], the Swedish Research Council (including grant no. 2014-6019), Carl Tryggers Foundation for scientific research (CTH), the Åforsk Foundation, the STandUP for Energy program, the Solar-era.net project "CNT-PV", and the Swedish Strategic Research Council (SSF, RMA15-0130). A.L. acknowledges the support from the Swedish Research Council (grant no. 2014-6463) and Marie Sklodowska-Curie Actions (Cofund, Project INCA 600398).

\section{REFERENCES}

(1) Kojima, A.; Teshima, K.; Shirai, Y.; Miyasaka, T. Organometal Halide Perovskites as Visible-Light Sensitizers for Photovoltaic Cells. J. Am. Chem. Soc. 2009, 131, 6050-6051.

(2) Lee, M. M.; Teuscher, J.; Miyasaka, T.; Murakami, T. N.; Snaith, H. J. Efficient Hybrid Solar Cells Based on Meso-Superstructured Organometal Halide Perovskites. Science 2012, 338, 643-647.

(3) Snaith, H. J. Perovskites: The Emergence of a New Era for LowCost, High-Efficiency Solar Cells. J. Phys. Chem. Lett. 2013, 4, 36233630 .

(4) https://www.nrel.gov/pv/assets/images/efficiency-chart.png.

(5) Yin, W.-J.; Shi, T.; Yan, Y. Unusual Defect Physics in $\mathrm{CH}_{3} \mathrm{NH}_{3} \mathrm{PbI}_{3}$ Perovskite Solar Cell Absorber. Appl. Phys. Lett. 2014, 104, 063903.

(6) Stranks, S. D.; Eperon, G. E.; Grancini, G.; Menelaou, C.; Alcocer, M. J. P.; Leijtens, T.; Herz, L. M.; Petrozza, A.; Snaith, H. J. Electron-Hole Diffusion Lengths Exceeding 1 Micrometer in an Organometal Trihalide Perovskite Absorber. Science 2013, 342, 341344.

(7) McMeekin, D. P.; Sadoughi, G.; Rehman, W.; Eperon, G. E.; Saliba, M.; Horantner, M. T.; Haghighirad, A.; Sakai, N.; Korte, L.; Rech, B.; Johnston, M. B.; Herz, L. M.; Snaith, H. J. A Mixed-Cation Lead Mixed-Halide Perovskite Absorber for Tandem Solar Cells. Science 2016, 351, 151-155.

(8) Eperon, G. E.; Leijtens, T.; Bush, K. A.; Prasanna, R.; Green, T.; Wang, J. T.-W.; McMeekin, D. P.; Volonakis, G.; Milot, R. L.; May, R.; Palmstrom, A.; Slotcavage, D. J.; Belisle, R. A.; Patel, J. B.; Parrott, E. S.; Sutton, R. J.; Ma, W.; Moghadam, F.; Conings, B.; Babayigit, A.; Boyen, H.-G.; Bent, S.; Giustino, F.; Herz, L. M.; Johnston, M. B.; McGehee, M. D.; Snaith, H. J. Perovskite-Perovskite Tandem Photovoltaics with Optimized Band Gaps. Science 2016, 354, 861-865.

(9) Bi, D.; Tress, W.; Dar, M. I.; Gao, P.; Luo, J.; Renevier, C.; Schenk, K.; Abate, A.; Giordano, F.; Baena, J.-P. C.; Decoppet, J.-D.; Zakeeruddin, S. M.; Nazeeruddin, M. K.; Grätzel, M.; Hagfeldt, A. Efficient Luminescent Solar Cells Based on Tailored Mixed-Cation Perovskites. Sci. Adv. 2016, 2, No. e1501170.

(10) Saliba, M.; Matsui, T.; Domanski, K.; Seo, J.-Y.; Ummadisingu, A.; Zakeeruddin, S. M.; Correa-Baena, J.-P.; Tress, W. R.; Abate, A.; Hagfeldt, A.; Grätzel, M. Incorporation of Rubidium Cations into Perovskite Solar Cells Improves Photovoltaic Performance. Science 2016, 354, 206-209.

(11) Saliba, M.; Matsui, T.; Seo, J.-Y.; Domanski, K.; Correa-Baena, J.-P.; Nazeeruddin, M. K.; Zakeeruddin, S. M.; Tress, W.; Abate, A.; Hagfeldt, A.; Grätzel, M. Cesium-Containing Triple Cation Perovskite Solar Cells: Improved Stability, Reproducibility and High Efficiency. Energy Environ. Sci. 2016, 9, 1989-1997.

(12) Pellet, N.; Gao, P.; Gregori, G.; Yang, T.-Y.; Nazeeruddin, M. K.; Maier, J.; Grätzel, M. Mixed-Organic-Cation Perovskite Photovoltaics for Enhanced Solar-Light Harvesting. Angew. Chem., Int. Ed. 2014, 53, 3151-3157.

(13) Schulz, P.; Edri, E.; Kirmayer, S.; Hodes, G.; Cahen, D.; Kahn, A. Interface Energetics in Organo-Metal Halide Perovskite-Based Photovoltaic Cells. Energy Environ. Sci. 2014, 7, 1377-1381. 
(14) Jacobsson, J. T.; Correa-Baena, J.-P.; Pazoki, M.; Saliba, M.; Schenk, K.; Grätzel, M.; Hagfeldt, A. Exploration of the Compositional Space for Mixed Lead Halogen Perovskites for High Efficiency Solar Cells. Energy Environ. Sci. 2016, 9, 1706-1724.

(15) Park, B.-w.; Philippe, B.; Jain, S. M.; Zhang, X.; Edvinsson, T.; Rensmo, H.; Zietz, B.; Boschloo, G. Chemical Engineering of Methylammonium Lead Iodide/bromide Perovskites: Tuning of Opto-Electronic Properties and Photovoltaic Performance. J. Mater. Chem. A 2015, 3, 21760-21771.

(16) Eperon, G. E.; Stranks, S. D.; Menelaou, C.; Johnston, M. B.; Herz, L. M.; Snaith, H. J. Formamidinium Lead Trihalide: A Broadly Tunable Perovskite for Efficient Planar Heterojunction Solar Cells. Energy Environ. Sci. 2014, 7, 982.

(17) Ummadisingu, A.; Steier, L.; Seo, J.-Y.; Matsui, T.; Abate, A.; Tress, W.; Grätzel, M. The Effect of Illumination on the Formation of Metal Halide Perovskite Films. Nature 2017, 545, 208-212.

(18) Leijtens, T.; Bush, K.; Cheacharoen, R; Beal, R.; Bowring, A.; McGehee, M. D. Towards Enabling Stable Lead Halide Perovskite Solar Cells; Interplay between Structural, Environmental, and Thermal Stability. J. Mater. Chem. A 2017, 5, 11483-11500.

(19) Asghar, M. I.; Zhang, J.; Wang, H.; Lund, P. D. Device Stability of Perovskite Solar Cells-A Review. Renewable Sustainable Energy Rev. 2017, 77, 131-146.

(20) Song, Z.; Abate, A.; Watthage, S. C.; Liyanage, G. K.; Phillips, A. B.; Steiner, U.; Graetzel, M.; Heben, M. J. Perovskite Solar Cell Stability in Humid Air: Partially Reversible Phase Transitions in the $\mathrm{PbI}_{2}-\mathrm{CH}_{3} \mathrm{NH}_{3} \mathrm{I}-\mathrm{H}_{2} \mathrm{O}$ System. Adv. Energy Mater. 2016, 6, 1600846.

(21) Han, Y.; Meyer, S.; Dkhissi, Y.; Weber, K.; Pringle, J. M.; Bach, U.; Spiccia, L.; Cheng, Y.-B. Degradation Observations of Encapsulated Planar $\mathrm{CH}_{3} \mathrm{NH}_{3} \mathrm{PbI}_{3}$ Perovskite Solar Cells at High Temperatures and Humidity. J. Mater. Chem. A 2015, 3, 8139-8147.

(22) Aristidou, N.; Sanchez-Molina, I.; Chotchuangchutchaval, T.; Brown, M.; Martinez, L.; Rath, T.; Haque, S. A. The Role of Oxygen in the Degradation of Methylammonium Lead Trihalide Perovskite Photoactive Layers. Angew. Chem., Int. Ed. 2015, 54, 8208-8212.

(23) Hoke, E. T.; Slotcavage, D. J.; Dohner, E. R.; Bowring, A. R.; Karunadasa, H. I.; McGehee, M. D. Reversible Photo-Induced Trap Formation in Mixed-Halide Hybrid Perovskites for Photovoltaics. Chem. Sci. 2015, 6, 613-617.

(24) Yoon, S. J.; Draguta, S.; Manser, J. S.; Sharia, O.; Schneider, W. F.; Kuno, M.; Kamat, P. V. Tracking Iodide and Bromide Ion Segregation in Mixed Halide Lead Perovskites during Photoirradiation. ACS Energy Lett. 2016, 1, 290-296.

(25) Slotcavage, D. J.; Karunadasa, H. I.; McGehee, M. D. LightInduced Phase Segregation in Halide-Perovskite Absorbers. ACS Energy Lett. 2016, 1, 1199-1205.

(26) Unger, E. L.; Kegelmann, L.; Suchan, K.; Sörell, D.; Korte, L.; Albrecht, S. Roadmap and Roadblocks for the Band Gap Tunability of Metal Halide Perovskites. J. Mater. Chem. A 2017, 5, 11401-11409.

(27) Rehman, W.; Milot, R. L.; Eperon, G. E.; Wehrenfennig, C.; Boland, J. L.; Snaith, H. J.; Johnston, M. B.; Herz, L. M. ChargeCarrier Dynamics and Mobilities in Formamidinium Lead MixedHalide Perovskites. Adv. Mater. 2015, 27, 7938-7944.

(28) Unger, E. L.; Hoke, E. T.; Bailie, C. D.; Nguyen, W. H.; Bowring, A. R.; Heumüller, T.; Christoforo, M. G.; McGehee, M. D. Hysteresis and Transient Behavior in Current-voltage Measurements of Hybrid-Perovskite Absorber Solar Cells. Energy Environ. Sci. 2014, 7, 3690-3698.

(29) Richardson, G.; O’Kane, S. E. J.; Niemann, R. G.; Peltola, T. A.; Foster, J. M.; Cameron, P. J.; Walker, A. B. Can Slow-Moving Ions Explain Hysteresis in the Current-Voltage Curves of Perovskite Solar Cells? Energy Environ. Sci. 2016, 9, 1476-1485.

(30) Belisle, R. A.; Nguyen, W. H.; Bowring, A. R.; Calado, P.; Li, X.; Irvine, S. J. C.; McGehee, M. D.; Barnes, P. R. F.; O’Regan, B. C. Interpretation of Inverted Photocurrent Transients in Organic Lead Halide Perovskite Solar Cells: Proof of the Field Screening by Mobile Ions and Determination of the Space Charge Layer Widths. Energy Environ. Sci. 2017, 10, 192-204.
(31) Jacobsson, T. J.; Correa-Baena, J.-P.; Anaraki, E. H.; Philippe, B.; Stranks, S. D.; Bouduban, M. E. F.; Tress, W.; Schenk, K.; Teuscher, J.; Moser, J.-E.; Rensmo, H.; Hagfeldt, A. Unreacted $\mathrm{PbI}_{2}$ as a DoubleEdged Sword for Enhancing the Performance of Perovskite Solar Cells. J. Am. Chem. Soc. 2016, 138, 10331-10343.

(32) Philippe, B.; Saliba, M.; Correa-Baena, J.-P.; Cappel, U. B.; Turren-Cruz, S.-H.; Grätzel, M.; Hagfeldt, A.; Rensmo, H. Chemical Distribution of Multiple Cation $\left(\mathrm{Rb}^{+}, \mathrm{Cs}^{+}, \mathrm{MA}^{+}\right.$, and $\left.\mathrm{FA}^{+}\right)$Perovskite Materials by Photoelectron Spectroscopy. Chem. Mater. 2017, 29, 3589-3596.

(33) Lindblad, R.; Bi, D.; Park, B.-w.; Oscarsson, J.; Gorgoi, M.; Siegbahn, H.; Odelius, M.; Johansson, E. M. J.; Rensmo, H. Electronic Structure of $\mathrm{TiO} 2 / \mathrm{CH} 3 \mathrm{NH} 3 \mathrm{PbI} 3$ Perovskite Solar Cell Interfaces. J. Phys. Chem. Lett. 2014, 5, 648-653.

(34) Philippe, B.; Park, B.-W.; Lindblad, R.; Oscarsson, J.; Ahmadi, S.; Johansson, E. M. J.; Rensmo, H. Chemical and Electronic Structure Characterization of Lead Halide Perovskites and Stability Behavior under Different Exposures-A Photoelectron Spectroscopy Investigation. Chem. Mater. 2015, 27, 1720-1731.

(35) Giangrisostomi, E.; Ovsyannikov, R.; Sorgenfrei, F.; Zhang, T.; Lindblad, A.; Sassa, Y.; Cappel, U. B.; Leitner, T.; Mitzner, R.; Svensson, S.; Mårtensson, N.; Föhlisch, A. Low Dose Photoelectron Spectroscopy at BESSY II: Electronic Structure of Matter in Its Native State. J. Electron Spectrosc. Relat. Phenom. 2017, DOI: 10.1016/ j.elspec.2017.05.011.

(36) Ovsyannikov, R.; Karlsson, P.; Lundqvist, M.; Lupulescu, C.; Eberhardt, W.; Föhlisch, A.; Svensson, S.; Mårtensson, N. Principles and Operation of a New Type of Electron Spectrometer-ArTOF. J. Electron Spectrosc. Relat. Phenom. 2013, 191, 92-103.

(37) Li, Y.; Xu, X.; Wang, C.; Ecker, B.; Yang, J.; Huang, J.; Gao, Y. Light-Induced Degradation of $\mathrm{CH}_{3} \mathrm{NH}_{3} \mathrm{PbI}_{3}$ Hybrid Perovskite Thin Film. J. Phys. Chem. C 2017, 121, 3904-3910.

(38) Zu, F.-S.; Amsalem, P.; Salzmann, I.; Wang, R.-B.; Ralaiarisoa, M.; Kowarik, S.; Duhm, S.; Koch, N. Impact of White Light Illumination on the Electronic and Chemical Structures of Mixed Halide and Single Crystal Perovskites. Adv. Opt. Mater. 2017, 5, 1700139.

(39) Sveinbjörnsson, K.; Aitola, K.; Zhang, J.; Johansson, M. B.; Zhang, X.; Correa-Baena, J.-P.; Hagfeldt, A.; Boschloo, G.; Johansson, E. M. J. Ambient Air-Processed Mixed-Ion Perovskites for HighEfficiency Solar Cells. J. Mater. Chem. A 2016, 4, 16536-16545.

(40) Förster, D. F.; Lindenau, B.; Leyendecker, M.; Janssen, F.; Winkler, C.; Schumann, F. O.; Kirschner, J.; Holldack, K.; Föhlisch, A. Phase-Locked MHz Pulse Selector for X-Ray Sources. Opt. Lett. 2015, 40, 2265.

(41) Manser, J. S.; Christians, J. A.; Kamat, P. V. Intriguing Optoelectronic Properties of Metal Halide Perovskites. Chem. Rev. 2016, 116, 12956-13008. 